\title{
RADIOCARBON DATING OF A VERY LARGE AFRICAN BAOBAB FROM LIMPOPO, SOUTH AFRICA: INVESTIGATION OF THE SAGOLE BIG TREE
}

\author{
ADRIAN PATRUT' ${ }^{\mathrm{a}, *}$, ROXANA T. PATRUT ${ }^{\mathrm{b}}$, \\ ROBERT VAN PELT', DANIEL A. LOWYd, EDIT FORIZS ${ }^{a}$, \\ JENÖ BODIS ${ }^{a}$, DRAGOS MARGINEANUa, \\ KARL F. VON REDEN ${ }^{\mathrm{e}}$
}

\begin{abstract}
The article reports the AMS (accelerator mass spectrometry) radiocarbon dating results of Sagole Big tree, a giant African baobab from Limpopo, South Africa. Several wood samples were collected from the walls of its inner cavity and dated by radiocarbon. The age values along the cavity samples increase with the distance into the wood. This anomaly shows that the cavity is a false one. The oldest sample segment had a radiocarbon date of $781 \pm 29 \mathrm{BP}$, which corresponds to a calibrated age of $740 \pm 15 \mathrm{yr}$. We estimate that the oldest part of the Sagole baobab has an age of 800-900 yr. We determined that the tree has a closed ring-shaped structure, which consists of a large unit with six fused stems and of two additional leaning stems.
\end{abstract}

Keywords: AMS radiocarbon dating, Adansonia digitata, tropical trees, ringshaped structure, age determination, false cavity.

a Babeş-Bolyai University, Faculty of Chemistry and Chemical Engineering, 11 Arany Janos, RO-400028, Cluj-Napoca, Romania.

b Babeş-Bolyai University, Faculty of Biology and Geology, 44 Gheorghe Bilascu, RO400015, Cluj-Napoca, Romania.

${ }^{c}$ Institute for Redwood Ecology, Humboldt State University, Arcata, CA 95521, U.S.A.

${ }^{d}$ Nova University, 5000 Dawes Ave., Alexandria, VA 22311, U.S.A.

e NOSAMS Facility, Dept. of Geology \& Geophysics, Woods Hole Oceanographic Institution, Woods Hole, MA 02543, U.S.A.

*Corresponding author: apatrut@gmail.com 


\section{INTRODUCTION}

In 2005 , we started a long-term research in order to elucidate several aspects related to the architecture, growth and age of the African baobab (Adansonia digitata L.). The research is mainly based on our approach which also allows to investigate and date standing and live baobab specimens. The methodology consists of AMS radiocarbon dating of small wood samples collected from inner cavities and/or deep incisions/entrances in the stems, fractured stems and from the outer part of large baobabs [1-5].

Owing to the special ability of baobabs to produce stems periodically during their life cycle, over time they develop architectures of increasing complexity. That is why our research focused on superlative baobabs, i.e., very large and/or old specimens. According to radiocarbon dating results, all large baobabs are multi-stemmed. We identified the open and closed ringshaped structures, which are the most important architectures that enable African baobabs to reach old ages and large sizes [6, 7]. Old baobabs have often large cavities, especially in the central area of their trunk/stems. In normal cavities generated by wood removal, the pith/centre of the stem is located inside the cavity. For wood samples extracted from normal cavities, age values decrease continuously from the cavity walls toward the outer part of the stem. Our research of large and old baobabs has identified a major anomaly in the age sequence of cavity samples dated by radiocarbon. In these cases, ages of samples collected from their inner cavities increase from the cavity walls up to a certain distance into the wood, after which they decrease toward the outer part. The only possible explanation for this finding is that such cavities are only natural empty spaces between several fused stems disposed in a closed ring-shaped structure, which were never filled with wood. We named them false cavities. The first significant difference between false and normal cavities is the presence or absence of the bark inside the cavity. Unlike normal cavities, which become larger over time due to continuous decay, false cavities tend to become smaller as a result of stem growth [7-10]. The oldest dated $A$. digitata individuals were found to have ages up to 2500 years [11, 12].

Dated growth rings of several investigated African baobab specimens, which may act as a proxy climate archive, were used for past climate reconstruction in southern Africa [13, 14].

Here we present the investigation results of a giant baobab, i.e., the Sagole Big tree from Limpopo Province, South Africa. The Sagole baobab is included in the Big Tree Register. According to a very controversial formula proposed by the Dendrological Society for calculating the tree size, it has a size index of 426 and it has been officially declared the largest Champion Tree of South Africa [15]. 


\section{RESULTS AND DISCUSSION}

The Sagole Big tree and its area. The Sagole Big tree is located in Zwigodini village at $54 \mathrm{~km}$ NNW of Tshipise, in Mutale Municipality, Vhembe District, Limpopo Province, South Africa. The GPS coordinates are $22^{\circ} 30.002^{\prime}$ $\mathrm{S}, 030^{\circ} 37.995^{\prime} \mathrm{E}$ and the altitude is $359 \mathrm{~m}$. Mean annual rainfall in the area is $354 \mathrm{~mm}$.

Mapping results. The Sagole Big tree consists of a very large unit, which is multi-stemmed and heavily buttressed; it also has two additional leaning stems (Figure 1). It has a maximum height of $19.8 \mathrm{~m}$, the circumference at breast height (cbh; at $1.30 \mathrm{~m}$ above ground level) is $34.35 \mathrm{~m}$ and the basal footprint of $60.6 \mathrm{~m}^{2}$, which corresponds to a formal diametre of $9.64 \mathrm{~m}$.

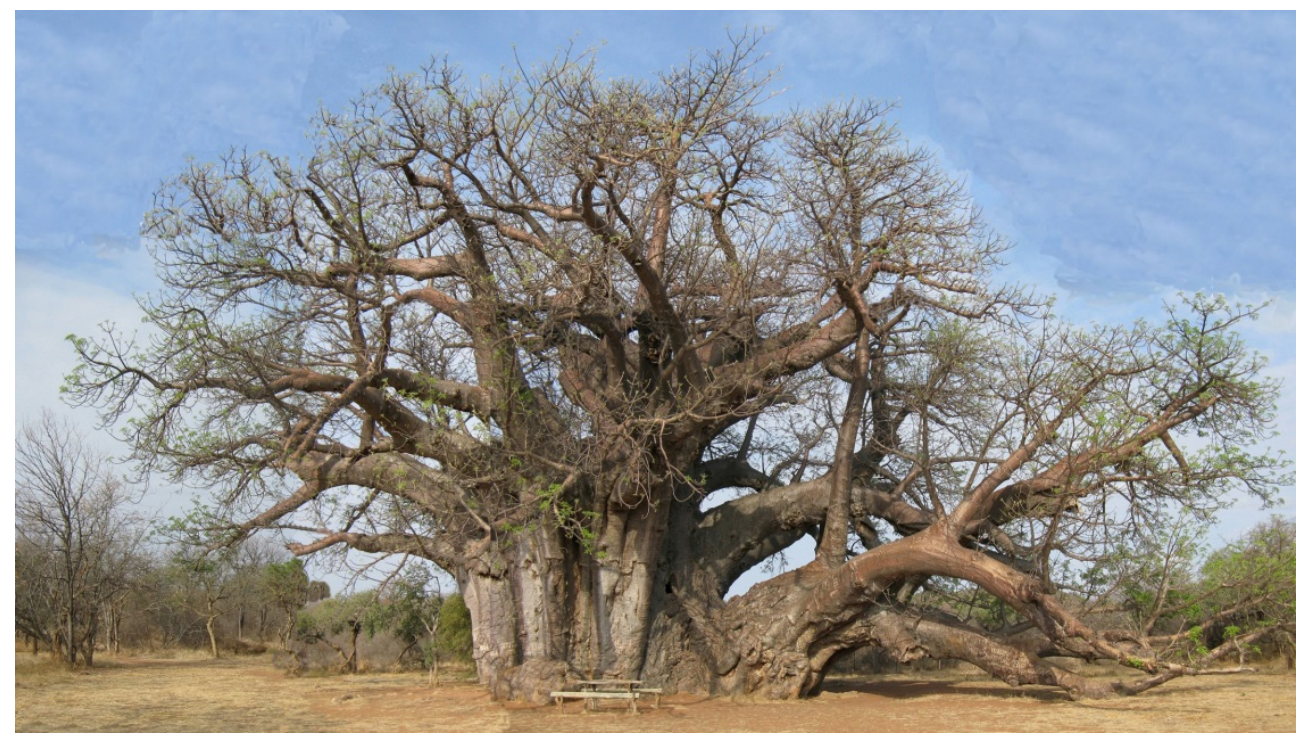

Figure 1. General view of the Sagole Big tree taken from the west.

The overall wood volume is $414 \mathrm{~m}^{3}$, out of which $252 \mathrm{~m}^{3}$ below $5 \mathrm{~m}$ and $162 \mathrm{~m}^{3}$ above $5 \mathrm{~m}$. After the recent splits of Platland tree, which had a total wood volume of $501 \mathrm{~m}^{2}$ [16], the Sagole Big tree becomes the largest African baobab (Figure 2). The canopy has a total volume of $16,032 \mathrm{~m}^{3}$ and a total surface of $134 \mathrm{~m}^{3}$, which corresponds to a mean crown diametre of $42.7 \mathrm{~m}$. 


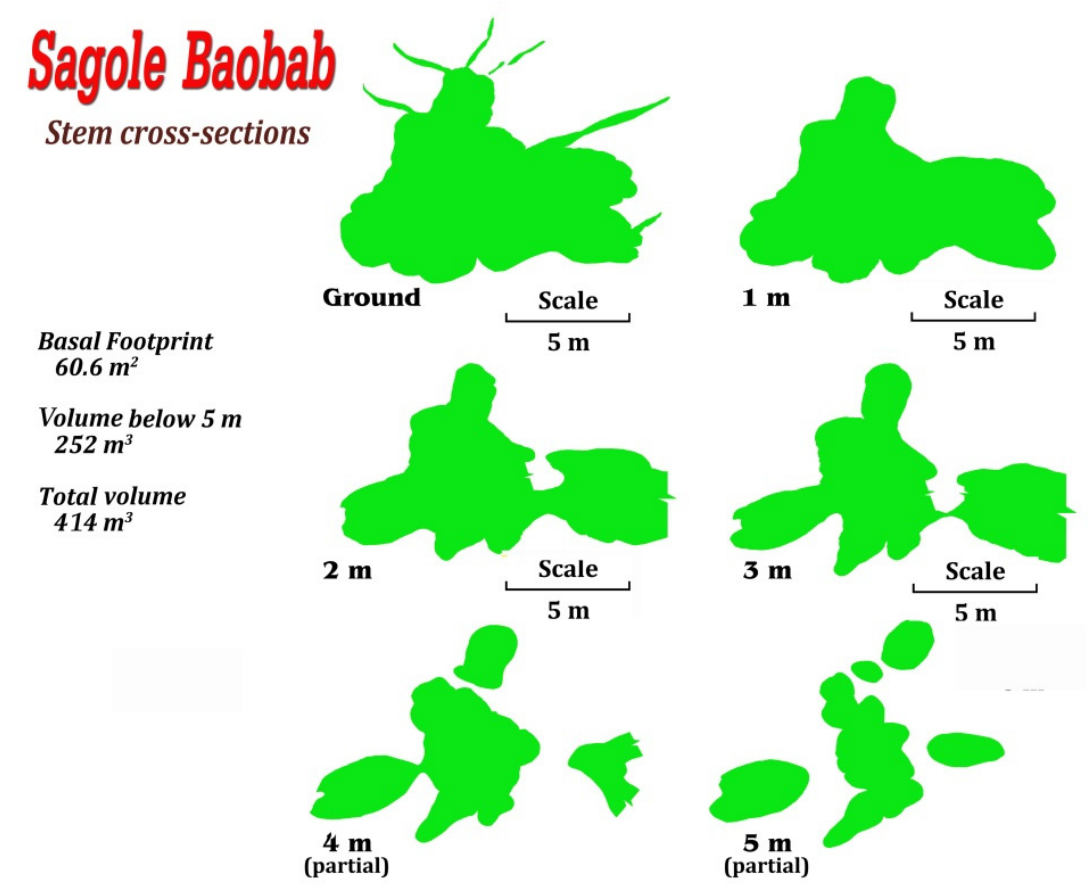

Figure 2. Cross sectional areas of the trunk/stems of Sagole tree at different heights (ground level, $1 \mathrm{~m}, 2 \mathrm{~m}, 3 \mathrm{~m}, 4 \mathrm{~m}$ and $5 \mathrm{~m}$ ).

The Sagole Big tree has a closed ring-shaped structure with a false cavity inside the large unit. The large unit consists of six fused main stems, out of which four build the ring and two are outside the ring. By also considering the two leaning stems, the Sagole baobab consists of eight stems.

The main part of the false cavity, which is covered by bark, has a length of $2.20 \mathrm{~m}$ (NS) and a width of $2.70 \mathrm{~m}(\mathrm{WE})$; the maximum height is $7.41 \mathrm{~m}$ and the basal surface $4.8 \mathrm{~m}^{2}$. The cavity also has an appendix toward the north, which is $1.10 \mathrm{~m}$ long, has a maximum width of $0.70 \mathrm{~m}$ and is not accessible. The entrance into the cavity is possible from the south via a small corridor with a length of $1.30 \mathrm{~m}$, a width between 0.70 and $1.00 \mathrm{~m}$ and a height of $3.90 \mathrm{~m}$ (Figure 3). Similarly to other false cavities, the cavity of Sagole tree is only an empty space between the stems that build the ring. This space which was never filled with wood becomes smaller over time, due to stem growth. There is also a kind of extension toward the south between the two leaning stems, like an uncovered aisle, with a length of $4.36 \mathrm{~m}$ and a width of $1.07 \mathrm{~m}$ at its end. 


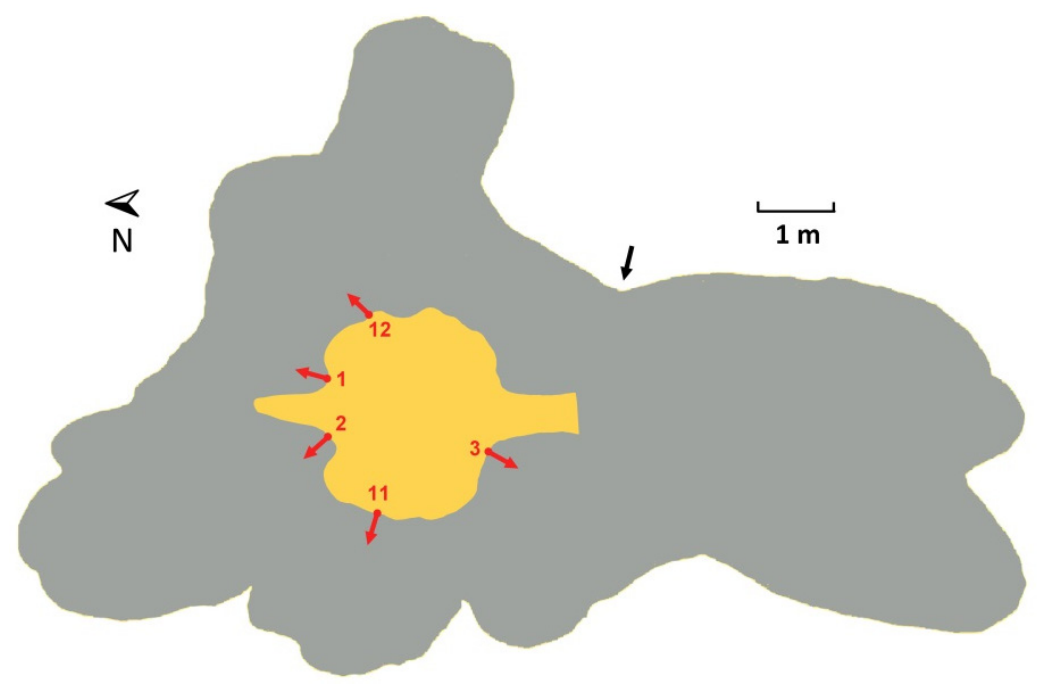

Figure 3. Cross-section of the Sagole tree (at $1 \mathrm{~m}$ above ground), showing the position of the false cavity, the positions of the five sampling points and the sampling directions.

Wood samples. Three wood samples (labelled 1-3) were collected from the northern and western walls of the false cavity, at low heights between 0.33 and $0.40 \mathrm{~m}$. The sample lengths were $0.56,0.33$ and $0.30 \mathrm{~m}$. Other two samples (labelled 11 and 12) were collected from the western and eastern walls of the cavity, at greater heights of 1.36 and $1.30 \mathrm{~m}$. These samples were 0.64 and $0.43 \mathrm{~m}$ long. A number of 13 small pieces/segments, each of the length of $0.001 \mathrm{~m}$ (marked as a, b, c), were extracted from determined positions of the five samples.

AMS results and calibrated ages. Radiocarbon dates of the 13 segments are listed in Table 1. Radiocarbon dates and errors were rounded to the nearest year. The radiocarbon dates are expressed in ${ }^{14} \mathrm{C}$ yr BP (radiocarbon years before present, i.e., before the reference year ad 1950). Calibrated (cal) ages, expressed in calendar years, are also displayed in Table 1. The 1- $\sigma$ probability distribution was selected to derive calibrated age ranges. For five sample segments, the 1- $\sigma$ distribution is consistent with only one range of calendar years. For the other eight sample segments, the 1- $\sigma$ distribution is consistent with two or three ranges of calendar years. For these eight segments, the confidence interval of one range is considerably greater than that of the other(s); therefore, it was selected as the cal $A D$ range of the segment for the purpose of this discussion. For obtaining single calendar age values of sample segments, we 
derived a mean calendar age of each segment from the selected range (marked in bold). Calendar ages of segments represent the difference between AD 2017 and the mean value of the selected range, with the corresponding error. Calendar ages and errors were rounded to the nearest $5 \mathrm{yr}$.

Table 1. AMS Radiocarbon dating results and calibrated calendar ages of samples/segments collected from the Sagole baobab.

\begin{tabular}{|c|c|c|c|c|}
\hline $\begin{array}{c}\text { Sample } \\
\text { (Segment) }\end{array}$ & $\begin{array}{l}\text { Depth }^{1} \\
\left.\text { [height }^{2}\right] \\
\left(10^{-2} \mathrm{~m}\right)\end{array}$ & $\begin{array}{c}\text { Radiocarbon date } \\
\text { [error] } \\
\left({ }^{14} \mathrm{C} \text { yr BP }\right) \\
\end{array}$ & $\begin{array}{c}\text { Cal AD range } \\
1-\sigma \\
\text { [confidence interval] }\end{array}$ & $\begin{array}{l}\text { Sample age } \\
\text { [error] } \\
\text { (cal yr) }\end{array}$ \\
\hline $1 \mathrm{a}$ & $\begin{array}{c}20 \\
{[33]}\end{array}$ & $195[ \pm 23]$ & $\begin{array}{c}1670-1696[20.6 \%] \\
1725-1784[38.2 \%] \\
1794-1808[9.4 \%]\end{array}$ & $260[ \pm 30]$ \\
\hline $1 \mathrm{~b}$ & $\begin{array}{c}46 \\
{[33]}\end{array}$ & $390[ \pm 18]$ & $\begin{array}{l}1478-1509[28.0 \%] \\
1580-1621[40.2 \%]\end{array}$ & $415[ \pm 20]$ \\
\hline $1 \mathrm{c}$ & $\begin{array}{c}56 \\
{[33]}\end{array}$ & $480[ \pm 25]$ & $1436-1458[68.2 \%]$ & $570[ \pm 10]$ \\
\hline $2 a$ & $\begin{array}{c}21 \\
{[33]}\end{array}$ & $197[ \pm 26]$ & $\begin{array}{c}1668-1696[19.2 \%] \\
1725-1786[39.7 \%] \\
1793-1808[9.4 \%]\end{array}$ & $260[ \pm 30]$ \\
\hline $2 b$ & $\begin{array}{c}33 \\
{[33]}\end{array}$ & $275[ \pm 21]$ & $1640-1668$ [68.2\%] & $365[ \pm 15]$ \\
\hline $3 a$ & $\begin{array}{c}10 \\
{[40]}\end{array}$ & $227[ \pm 18]$ & $\begin{array}{c}1667-1672[6.2 \%] \\
1741-1796[\mathbf{4 2 . 0 \%}]\end{array}$ & $250[ \pm 25]$ \\
\hline $3 b$ & $\begin{array}{c}20 \\
{[40]}\end{array}$ & $335[ \pm 27]$ & $\begin{array}{l}\mathbf{1 5 1 0 - 1 5 7 6}[\mathbf{5 2 . 0} \%] \\
1622-1640[16.2 \%]\end{array}$ & $475[ \pm 35]$ \\
\hline $3 c$ & $\begin{array}{c}30 \\
{[40]}\end{array}$ & $436[ \pm 21]$ & $1452-1490[68.2 \%]$ & $545[ \pm 20]$ \\
\hline $11 a$ & $\begin{array}{c}20 \\
{[136]}\end{array}$ & $270[ \pm 19]$ & $1644-1668[68.2 \%]$ & $360[ \pm 10]$ \\
\hline $11 \mathrm{~b}$ & $\begin{array}{c}40 \\
{[136]}\end{array}$ & $530[ \pm 25]$ & $1419-1442[68.2 \%]$ & $590[ \pm 10]$ \\
\hline $11 \mathrm{c}$ & $\begin{array}{c}64 \\
{[136]}\end{array}$ & $781[ \pm 29]$ & $\begin{array}{l}1234-1244[12.2 \%] \\
1264-1291[56.0 \%]\end{array}$ & $740[ \pm 15]$ \\
\hline $12 a$ & $\begin{array}{c}25 \\
{[130]}\end{array}$ & $212[ \pm 20]$ & $\begin{array}{c}1670-1688[8.8 \%] \\
1734-1784[53.8 \%] \\
1794-1800[5.6 \%]\end{array}$ & $260[ \pm 25]$ \\
\hline $12 b$ & $\begin{array}{c}43 \\
{[130]}\end{array}$ & $333[ \pm 24]$ & $\begin{array}{l}\mathbf{1 5 1 0 - 1 5 5 1}[\mathbf{3 7 . 0 \%}] \\
1558-1574[12.4 \%] \\
1622-1642[18.8 \%]\end{array}$ & $485[ \pm 20]$ \\
\hline
\end{tabular}

${ }^{1}$ Depth in the wood from the sampling point.

${ }^{2}$ Height above ground level. 
Dating results of samples (segments). We extracted and dated two or three segments from each sample. For all five samples, the ages of segments increase with the distance into the wood. Consequently, the oldest segments were extracted from the sample ends. For the first three samples collected at lower heights, labelled 1-3, the oldest dated segments, i.e., 1c and 3c, correspond to distances of $0.56 \mathrm{~m}$ and $0.30 \mathrm{~m}$ into the wood. Their radiocarbon dates of $480 \pm 20$ and $436 \pm 21 \mathrm{BP}$ correspond to calibrated ages of $570 \pm 10$ and $545 \pm$ 20 calendar yr. For samples 11 and 12 collected at greater heights, the oldest segment $11 \mathrm{c}$, which is also the deepest, was positioned at $0.64 \mathrm{~m}$ from the sampling point. Its radiocarbon date of $781 \pm 29 \mathrm{BP}$ corresponds to a calibrated age of $740 \pm 15$ calendar yr.

Architecture and age of the Sagole tree. For the five samples collected from the cavity, the age values increase with the depth into the wood. This anomaly is characteristic only to false cavities. We already mentioned that the Sagole baobab has a closed ring-shaped structure with a false cavity inside the ring.

The tree is composed of a large unit, which consists of six fused main stems, and two leaning stems.

For baobabs that exhibit a closed ring-shaped structure, the oldest stems are always around the false cavity. The oldest dated sample segment $11 \mathrm{c}$ has an age of $740 \pm 15 \mathrm{yr}$. The segment originates from a distance of $0.64 \mathrm{~m}$ from the inner cavity walls. In this area, the depth of the cavity walls was of $1.60 \mathrm{~m}$. Taking into account our previous research on age sequences along samples collected from stems that build the ring, we consider that the position of segment 11c was close to the point of maximum age in the corresponding direction. Therefore, we estimate that in the point of maximum age, this stem has an age of $800-900 \mathrm{yr}$, i.e., $850 \pm 50 \mathrm{yr}$. The age of the two stems of the large unit which grow outside the ring, as well as the age of the two leaning stems, that have not been dated, must be considerably lower than the ring, probably up to $500-600 \mathrm{yr}$.

The age of 800-900 yr for the oldest part of Sagole tree determined via radiocarbon dating, is considerably younger than the age values proposed by other tree researchers. Such high values were suggested by considering the girth of the baobab, which is exaggerated by the buttresses and especially by the leaning stems, but also by the overall size which is due to the large number of stems that build the tree. On the other hand, the age we determined for the Sagole tree is comparable to the age of the large unit of the Platland tree, which toppled and died recently [16]. Finally, we mention that the largest trees are usually not the oldest. The largest specimens are those which had grown very fast when they were young and continued their rapid growth [5]. 


\section{CONCLUSIONS}

The research discloses the main results of the radiocarbon investigation of a giant African baobab, the Sagole Big tree, located in the Limpopo Province, South Africa. The main aim of the research was to determine the architecture and age of the baobab, as well as its accurate size. With a total wood volume of $414 \mathrm{~m}^{3}$, the Sagole Big tree has just become the largest known African baobab. Five wood samples were collected from the walls of its inner cavity. The age values of segments extracted from these samples increase with the distance into the wood. This anomaly is specific to false cavities. The oldest sample segment had a radiocarbon date of $781 \pm 29 \mathrm{BP}$, which corresponds to a calibrated age of $740 \pm 15$ calendar yr. Based on dating results and accurate measurements, we consider that the oldest part of the Sagole baobab has an age of 800-900 yr. The tree exhibits a closed ring-shaped structure with a false cavity inside. It consists of a large six-stemmed unit and of two additional leaning stems.

\section{EXPERIMENTAL SECTION}

Measurements. The external measurements of the Sagole Big tree and the measurements inside the inner cavity was performed by using a Bosch DLE 70 Professional laser rangefinder (Robert Bosch $\mathrm{GmbH}$, Stuttgart, Germany) and graduated tapes. Cross-sections of the baobab at ground level, 1, 2, 3, 4 and $5 \mathrm{~m}$ were mapped by setting up a frame around the tree with a graduated tape. A compass and an Impulse 200 laser rangefinder (Laser Technology, Inc., Centennial, CO, U.S.A.) were used to map the cross-sections. Additional cross-sections on the largest section were mapped at 6.5 and $8 \mathrm{~m}$. All of the mostly round branch and stem sections above or around this had their basal diameters estimated by using a Criterion 400 survey laser (Laser Technology, Inc., Centennial, CO, U.S.A.). System lengths were either measured directly or interpreted from detailed photos of the tree structure without leaves. Parabolic or conic equations were used for these smaller systems based on how robust and foliated each system was.

Sample collection. The wood samples were collected from the false cavity walls in the time frame 2008-2011, by using Haglöf CH $600(0.60 \mathrm{~m}$ long, $0.0054 \mathrm{~m}$ inner diametre) and Haglöf $\mathrm{CH} 800(0.80 \mathrm{~m}, 0.0108 \mathrm{~m})$ increment borers. A number of tiny pieces/segments of the length of $0.001 \mathrm{~m}$ were extracted from each wood sample. The segments were processed and investigated by AMS radiocarbon dating. 
Sample preparation. AMS measurements. See our first article in this issue [16].

Calibration. Radiocarbon dates were converted into calendar ages with OxCal v4.2 for Windows [17], using the SHCal13 atmospheric set [18].

\section{ACKNOWLEDGMENTS}

Authors thank Diana H. Mayne and Sarah Venter for collecting samples, for participating in field investigations of the baobab and for helpful discussions. The research was funded by the Romanian Ministry of Scientific Research CNCSUEFISCDI under grant PN-II-ID-PCE-2013-76.

\section{REFERENCES}

1. G.E. Wickens, P. Lowe, "The Baobabs: Pachycauls of Africa, Madagascar and Australia", Springer, Dordrecht, 2008.

2. A. Patrut, K.F. von Reden, D.A. Lowy, A.H. Alberts, J.W. Pohlman, R.Wittmann, D. Gerlach, L. Xu, C. Mitchell, Tree Physiology, 2007, 27, 15691574.

3. A. Patrut, D.H. Mayne, K.F. von Reden, D.A. Lowy, S. Venter, A.P. McNichol, M.L. Roberts, D. Margineanu, Radiocarbon, 2010, 52, 727-734.

4. A. Patrut, D.H. Mayne, K.F. von Reden, D.A. Lowy, R. Van Pelt, A.P. McNichol, M. L. Roberts, D. Margineanu, Radiocarbon, 2010, 52, 717-726.

5. A. Patrut, K.F. von Reden, R. Van Pelt, D.H. Mayne, D.A. Lowy, D. Margineanu, Annals of Forest Science, 2011, 68, 993-1003.

6. A. Patrut, S. Woodborne, K.F. von Reden, G. Hall, M. Hofmeyr, D. Lowy, R.T. Patrut, PLoS ONE, 2015, 10(1), e0117193, doi: 10.1371/journal. pone.0117193.

7. A. Patrut, S. Woodborne, R.T. Patrut, G. Hall, L. Rakosy, K.F. von Reden, D.A. Lowy, D. Margineanu, Studia UBB Chemia, 2015, LX, 4, 7-20.

8. A. Patrut, L. Rakosy, R.T. Patrut, I.A. Ratiu, E. Forizs, D.A. Lowy, D. Margineanu, K.F. von Reden, Studia UBB Chemia, 2016, LXI, 4, 7-20.

9. A. Patrut, R.T. Patrut, L. Rakosy, J. Bodis, D.A. Lowy, E. Forizs, K.F. von Reden, Studia UBB Chemia, 2016, LXI, 4, 21-30.

10. A. Patrut, S. Garnaud, O. Ka, R.T. Patrut, T. Diagne, D.A. Lowy, E. Foris, J. Bodis, K.F. von Reden, Studia UBB Chemia, 2017, LXII, 1, 111-120, doi:10.24193/subbchem.2017.1.09.

11. A. Patrut, K.F. von Reden, D.H. Mayne, D.A. Lowy, R.T. Patrut, Nuclear Instruments and Methods in Physics Research Section B, 2013, 294, 622626,doi: 10.1016/j.nimb.2012.04.025. 
12. A. Patrut, S. Woodborne, K.F. von Reden, G. Hall, R.T. Patrut, L. Rakosy, P. Danthu, J-M. Leong Pock-Tsy, D.A. Lowy, D. Margineanu, Radiocarbon, 2017, 59(2), 435-448, doi:10.1017/RDC.2016.92.

13. S. Woodborne, G. Hall, I. Robertson, A. Patrut, M. Rouault, N.J. Loader, M. Hofmeyr, PLOS ONE, 2015, 10(5), e0124202, doi:10.1371/journal.pone.0124202.

14. S. Woodborne, P. Gandiwa, G. Hall, A. Patrut, J. Finch, PLoS ONE 2016, 11(7), e015936. doi:10.1371/journal.pone.0159361.

15. N. Esterhuyse, J. von Breitenbach, H. Söhnge, I. van der Merwe, "Remarkable Trees of South Africa" second edition, Briza, Pretoria, 2016.

16. A. Patrut, S. Woodborne, R.T.Patrut, L.Rakosy, G. Hall, I.A. Ratiu, K.F. von Reden, Studia UBB Chemia, 2017, 62(2), 347-354, doi: 10.24193/subbchem.2017.2.27.

17. C. Bronk Ramsey, Radiocarbon, 2009, 51, 337-360.

18. A.G. Hogg, Q. Hua, P.G. Blackwell, M. Niu, C.E. Buck, T.P. Guilderson, T.J. Heaton, J.G. Palmer, P.J. Reimer, R.W. Reimer, C.S.M. Turney, R.H. Zimmerman, Radiocarbon, 2013, 55, 1889-1903. 